\title{
The Antibacterial Effects of the Mixture of Silver Nanoparticles With the Shallot and Nettle Alcoholic Extracts
}

\author{
Sepideh Zeynali Aghdam ${ }^{1,2}$, Sara Minaeian ${ }^{2 *}$, Meisam Sadeghpour Karimii ${ }^{3}$, Akram Sadat Tabatabaee Bafroee ${ }^{1}$ \\ ${ }^{1}$ Department of Biology, East Tehran Branch, Islamic Azad University, Tehran, Iran \\ ${ }^{2}$ Antimicrobial Resistance Research Center, Institute of Immunology and Infectious Diseases, Iran University of Medical Sciences, \\ Tehran, Iran \\ ${ }^{3}$ Center of Excellence in Electrochemistry, University of Tehran, Tehran, Iran
}

Corresponding Author: Sara Minaeian, PhD, Assistant Professor, Antimicrobial Resistance Research Center, Institute of Immunology and Infectious Diseases, Iran University of Medical Sciences, Tehran, Iran. Tel: +98-64352306, Email: sara.minaeian@gmail.com

Received February 16, 2019; Accepted August 23, 2019; Online Published December 5, 2019

\begin{abstract}
Introduction: Today, one of the most important challenges of the therapeutic system is the resistance of bacteria against different antibiotics especially in intensive care units which lead to an increase in hospitalization time and the patients' expenses. Acinetobacter baumannii is one of the most significant contaminating bacteria in intensive care units which has exhibited resistance against different antibiotics in recent years. The aim of this study was to investigate the synergism effect of the silver nanoparticles with the shallot and nettle alcoholic extracts against the standard and multidrug resistant $A$. baumannii isolates.

Materials and Methods: Samples were collected from intensive care units and the A. baumannii isolates were identified using biochemical tests. Then, the antibiogram test was carried out for each isolate. The antibacterial effect of nanoparticles, shallot and nettle extracts was evaluated singularly and in combination with each other against standard and resistant $A$. baumannii isolates. Measuring the diameter of inhibited growth zone, MIC, MBC and checkerboard tests were conducted for each isolate.

Results: The results showed that the silver nanoparticles, shallot and nettle alcoholic extracts each had antibacterial property against the standard and resistant $A$. baumannii isolates. The mixture of the nettle extract with silver nanoparticles had a synergism effect against the standard and resistant isolates and the mixture of the shallot extract with silver nanoparticles had an additive effect against $A$. baumannii isolates.

Conclusions: Due to the increase of antibiotics resistance and the resistance to the pathogenic bacteria especially in intensive care units, it is necessary to find effective and accessible substances to destroy the resistant bacteria and reduce the mortality rate of patients. The results of the present study revealed that the antibacterial property of the shallot and the nettle alcoholic extracts could increase the antibacterial property of the silver nanoparticles. As a result, these can be used for disinfecting different wards of a hospital, in particular, the intensive care units. Keywords: Acinetobacter baumannii, Hospital Infection, Antibiotic Resistance, Silver Nanoparticles, Nettle Extract, Shallot Extract

Citation: Zeynali Aghdam S, Minaeian S, Sadeghpour Karimi M, Tabatabaee Bafroee AS. The antibacterial effects of the mixture of silver nanoparticles with the shallot and nettle alcoholic extracts. J Appl Biotechnol Rep. 2019;6(4):158-164. doi:10.29252/JABR.06.04.05.
\end{abstract}

\section{Introduction}

The extensive consumption of antibiotics has undesired effects on hosts including high sensitivity, suppressing the immune system, and the allergic reactions in addition to making bacteria resistant. ${ }^{1,2}$ The problems raised by resistant bacteria have caused several challenges in the therapeutic system. ${ }^{2}$ Nowadays, the spread of Gram-negative pathogens resistant to drugs in hospitals has become a great problem, and is rising in many countrie. ${ }^{3}$ Acinetobacter is one of these pathogens which are found in different wards of hospitals, especially in intensive care units (ICUs). The resistance among Acinetobacter spp. has increased dramatically in recent years and has become a global threat. ${ }^{4}$ Acinetobacter is one important reason for pneumonia and blood infections in the ICU..$^{5-7}$ Currently, it is necessary to find some stronger and more effective antibacterial substance against multi-drug resistant bacteria. ${ }^{2}$
From many years ago, medicinal plants have been used for the treatment of different infections. ${ }^{8}$ Nowadays, these plants have attracted the attention researchers because of their significant attributes including their strong antibacterial property, being cheap, and accessible. ${ }^{9,10}$ One of these medicinal plants which are local in Iran is the shallot (Allium hirtifolium) which has different therapeutic applications. ${ }^{11}$ The Iranian shallot is a member of the Allium family and has bulbs (short stem with meaty leaves). This plant is rich in combinations of organosulfur and flavonoids, and due to these combinations it has a strong anti-oxidant and antibacterial activity. Conducted investigations have shown that the aqueous and alcoholic extracts of the stems and the leaves of this plant have a strong antibacterial property. ${ }^{12-14}$ The nettle has a long history in treating different diseases and has been used in traditional medicine too. ${ }^{15}$ Different studies have revealed that the nettle extract has strong antibacterial

Copyright (C) 2019 The Author(s). This is an open-access article distributed under the terms of the Creative Commons Attribution License (http:// creativecommons.org/licenses/by/4.0), which permits unrestricted use, distribution, and reproduction in any medium, provided the original work is properly cited. 
effects especially against gram-negative bacteria. ${ }^{16-18}$

Nowadays, the different properties of substances can be changed by changing the size of the particles. ${ }^{19}$ Silver nanoparticles have an effective antibacterial property due to their large surface area. ${ }^{20}$ It is important to study the antibacterial effect of silver and the other nanoparticle compounds against the increasing resistance to gramnegative and gram-positive bacteria. ${ }^{21}$ Recently, the antibacterial properties of the mixture of plant extracts and silver nanoparticles against resistant bacteria have been investigated, and new hope has been gained. ${ }^{22}$

Therefore, it is necessary to use and find some new and effective compounds against resistant bacteria. The aim of the present study was to investigate the antibacterial effect of the shallot and nettle alcoholic extracts in combination with the silver nanoparticles against the standard and resistant $A$. baumannii isolates.

\section{Material and Methods}

Material

All the media were purchased from Merck, Germany. The entire antibiogram discs were purchased from Patan Teb Co., Iran. The standard strain was provided by the Institute of Immunology and Infectious Diseases, Iran University of Medical Sciences, Tehran, Iran.

\section{Collecting the Sample}

In order to conduct this research, $120 \mathrm{Mini}-\mathrm{BAL}$ samples were collected from the ICUs of the Rasool-e-Akram hospital in Tehran during September 2017- September 2018. All samples were investigated after transferring to the Immunology and Infectious Disease Institute of Iran Medical Sciences University for determining the bacterial identity. Samples were cultured on blood agar, nutrient agar, and McConkey agar and were incubated for 24 hours in $37^{\circ} \mathrm{C}$. Acinetobacter isolates were separated using microscopic and biochemical test methods.

\section{Antibiotic Sensitivity Test}

The disc diffusion test was conducted for all A. baumannii isolates according to the CLSI 2017 instruction. ${ }^{23}$ The bacterial suspension was prepared with the concentration of $5 \times 10^{5} \mathrm{CFU} / \mathrm{mL}$ and was transferred to the Muller-Hilton agar medium. The antibiotic discs were placed on the MullerHilton agar medium and were incubated at $35^{\circ} \mathrm{C}$ for 18 hours. The diameter of the inhibition zone was calculated and the resistant or susceptible bacteria were characterized using the CLSI standard table. All antibiotic disks were purchased from the MAST Company, UK. The antibiotic discs included trimethoprim $(25 \mu \mathrm{g})$, meropenem $(10 \mu \mathrm{g})$, amikacin $(30 \mu \mathrm{g})$, gentamicin $(10 \mu \mathrm{g})$, ceftazidime $(30 \mu \mathrm{g})$, sulfamethoxazole $(10$ $\mu \mathrm{g})$, colistin $(10 \mu \mathrm{g})$, imipenem $(10 \mu \mathrm{g})$, ampicilin-sulbactam $(10+10 \mu \mathrm{g})$, and piperacillin-tazobactam $(100+10 \mu \mathrm{g})$. Acinetobacter ATCC 19606 was used as a standard.

\section{Alcoholic Extracts}

The shallot and nettle extracts were purchased from the Ebnemasouyeh Pharmaceutical Company.
Preparing Silver Nanoparticles

The silver nanoparticles were synthesized by using sodium borohydride as a reducing agent. A hundred milliliters of 0.1 $(\mathrm{mM})$ silver nitrate and $30 \mathrm{ml}$ of $1(\mathrm{mM})$ sodium borohydride were prepared and chilled in an ice bath for 15 minutes. Then, the silver nitrate was added to sodium borohydride which had been stirred vigorously. Then the solution turned to light yellow. ${ }^{24}$ After preparing the solution, the nanoparticles were investigated with the help of FE-SEM, UV-Vis spectrum and X-ray powder diffraction (XRD). The as-synthesized nanoparticles were characterized by field emission scanning electron microscope (FE-SEM). The FE-SEM images were recorded on a Hitachi S-4160 instrument. The XRD analysis was carried out on a Rigaku D/max $2500 \mathrm{~V}$ diffractometer equipped with the graphite monochromator and $\mathrm{Cu}$ target. The UV-Vis spectra of the nanoparticles were recorded by Perkin-Elmer Lambda 25 UV/Vis spectrometer.

\section{Well Diffusion Test}

Resistant A. baumannii isolates were selected and used for preparing bacterial suspension. The bacterial suspensions were cultured using a sterile swab on Muller-Hinton agar (MHA) medium. Some wells with $6 \mathrm{~mm}$ diameter were created in the media. An amount of $100 \mu \mathrm{L}$ of nettle, shallot alcoholic extracts, and the silver nanoparticles were added to each well respectively. Then, they were incubated at $37^{\circ} \mathrm{C}$, and the inhibition zone diameter was measured. ${ }^{25}$

\section{Determination of Minimum Inhibitory Concentration}

The liquid dilution method was used to determine the minimum inhibitory concentration (MIC) of extracts and silver nanoparticles in accordance with CLSI (2011) guidelines. The MIC test was carried out through broth micro-dilution method. An amount of $100 \mu \mathrm{L}$ of sterile Mueller-Hinton broth was added into each of the 96-well round-bottomed sterilized microtiter plates. The nettle and shallot extracts, along with the silver nanoparticles solution were each separately poured into the wells and serially diluted in the Mueller-Hinton broth. Acinetobacter isolates were cultured in nutrient broth at $37^{\circ} \mathrm{C}$ overnight. Then, $20 \mu \mathrm{L}$ of fresh bacteria $\left(1.5 \times 10^{5} \mathrm{CFU} / \mathrm{mL}\right)$ was prepared in MullerHinton broth and was added. Microliter plates were covered with a sterile plate sealer and incubated at $37^{\circ} \mathrm{C}$ for $18-24$ hours. The growth of the bacteria was assessed as a function of turbidity (optical density [OD] at $600 \mathrm{~nm}$ ). ${ }^{26}$

\section{Determination of the Minimum Bactericidal Concentration} The minimum bactericidal concentration (MBC) of samples was determined following the MIC assay. The lowest concentration that kills all the bacteria was taken as MBC. The samples without any growth were selected from wells and were poured into a Petri dish. Then, $15 \mathrm{~mL}$ of MHA were inserted and left to solidify. All the Petri dish were incubated at $35^{\circ} \mathrm{C}$ for $18-24$ hours. The plate which had no bacterial growth was recorded as the MBC. ${ }^{27}$

\section{Checkerboard Assay}

The FIC measurement was evaluated to determine the 
interaction of the nettle alcoholic extract with the silver nanoparticles as well as the interaction of the shallot alcoholic extract with the silver nanoparticles against the selected ATCC (standard) and one of the resistant isolates (A6). The reaction of these compounds was evaluated using the checkerboard method and Sum FIC index. ${ }^{25}$

Fifty microliters of the mixture of shallot extract with the silver nanoparticles were added to each well of the microplate. A hundred microliters of bacterial suspension $\left(1.5 \times 10^{8} \mathrm{CFU} /\right.$ $\mathrm{mL}$ ) was added in each well. Nettle extract was diluted along the vertical axis of the micro-dilution plate, and the silver nanoparticles plate was diluted along the horizontal axis serially. Each microplate contained the positive and negative control. The positive control wells contained bacterial suspension and Muller Hinton broth, and the negative control wells contained different dilutions of (combination of the nettle extract with the silver nanoparticles) and the Muller Hinton broth without bacteria. The microplate was incubated in an incubator with the shaker at $37^{\circ} \mathrm{C}$ for 24 hours. All the steps were also repeated for the combination of the shallot extract with the silver nanoparticles. The following formula was used to determine the interaction of the plant extract with the silver nanoparticles (FIC):

$$
\text { Sum } \text { FIC }_{\mathrm{BC}}=\frac{\text { MICB in combination }}{\text { MICB alone }}+\frac{\text { MICC in combination }}{\text { MICC alone }}
$$

Sum FIC $_{\mathrm{BC}}$ The total differential inhibitory concentration of the extract and the silver nanoparticles

B: Alcoholic extract

C: Silver nanoparticles

$\mathrm{MIC}_{\mathrm{B}:}$ The minimum inhibitory concentration of the alcoholic extract

$\mathrm{MIC}_{\mathrm{C}}$ The minimum inhibitory concentration of the silver nanoparticles

The values below 0.9 show the synergism effect, the values between 0.9-1.1 show the additive effect and the values higher than 1.1 show the antagonistic effect. ${ }^{28}$

\section{Results}

Antibiogram Test

All the samples were identified by a microscopic test. The susceptibility of $A$. baumannii isolates to antibiotics was studied using the antibiogram test. The results of the antibiogram test for some isolates are shown in Table 1. In this study, MDR A. baumannii isolates were resistant to at least 3 different classes of antibiotics for example meropenem, ceftazidime and trimethoprim-sulfamethoxazole.

Evaluation of the Produced Silver Nanoparticles

The UV-Vis spectrum was recorded by Perkin-Elmer Lambda $25 \mathrm{UV}-\mathrm{Vis}$ spectrometer (Figure 1). The silver nanoparticles peaked at $420 \mathrm{~nm}$ confidence. ${ }^{29}$ The FE-SEM images were recorded on a Hitachi S-4160 instrument using a gold film for loading the dried particles on the instrument. The results have been shown in Figure 2. As shown in the FESEM image, the silver nanoparticles have a spherical shape and their average size is $50-80 \mathrm{~nm}$ in diameter. XRD analysis was carried out
Table 1. The Results of Evaluating the Antibiogram test for A. baumannii Isolates

\begin{tabular}{lccccccc}
\hline \multirow{2}{*}{ Antibiotic } & \multicolumn{6}{c}{ Acinetobacter Isolates } \\
\cline { 2 - 7 } & ATCC & AR & A6 & A81 & A223 & A194 \\
\hline Amikacin (AN30) & S & R & R & S & R & R \\
Meropenem (MEN10) & S & R & R & R & R & R \\
Trimethoperin-Sulfamethoxazole (SXT) & S & R & R & R & R & R \\
\hline Ceftazidime (CAZ30) & S & R & R & S & R & R \\
Gentamycin (GM10) & S & R & R & S & R & R \\
Imipenem (IMI10) & S & R & R & R & R & R \\
Piperacillin-Tazobactam (PTZ110) & S & R & R & R & R & R \\
Ampicilin-Sulbactam (SAM) & S & R & I & R & R & R \\
Colistin (CL10) & S & R & R & R & S & S \\
\hline
\end{tabular}

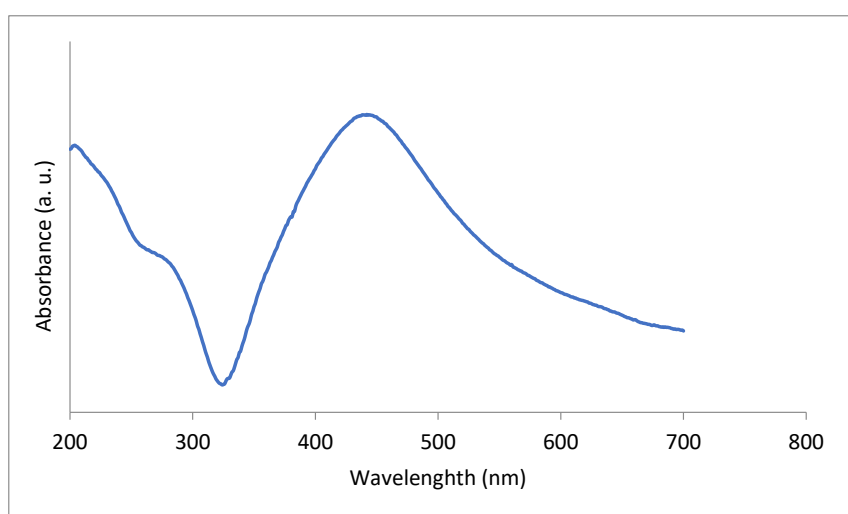

Figure 1. UV-Vis Spectrum of As-synthesized Silver Nanoparticles.

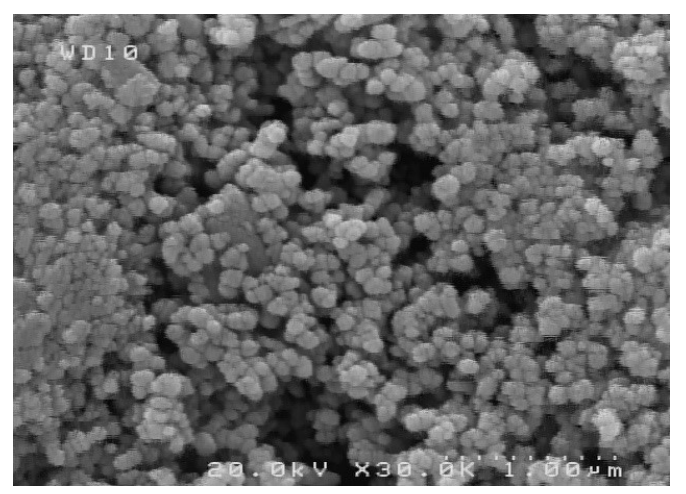

Figure 2. FESEM Image of As-Synthesized Silver Nanoparticles.

on a Rigaku D/max $2500 \mathrm{~V}$ diffractometer equipped with the graphite monochromator and $\mathrm{Cu}$ target. Figure 3 shows the XRD pattern of the as-synthesized silver nanoparticles. The strong intensity and no additional peaks in the pattern indicated the high crystallinity and purity of the product. Furthermore, all the diffraction peaks are in correspondence with a cubic structure with the JCPDS reference code 01-0870597.

\section{Well Diffusion}

The diameter of the inhibition zone of the nettle extract, shallot extract and the silver nanoparticles against A. baumannii isolates have been presented in Figure 4. The maximum size 


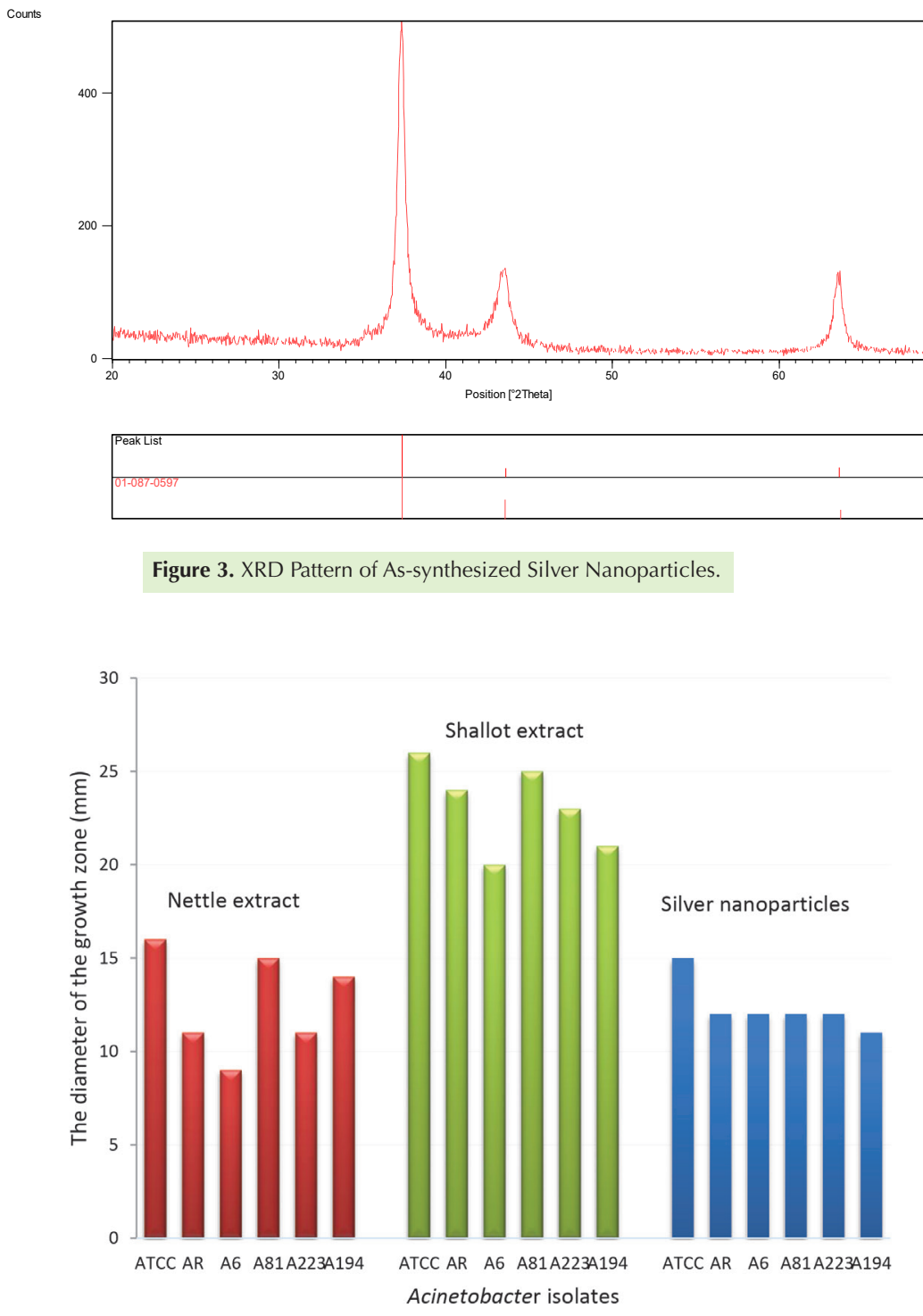

Figure 4. The Results of Evaluating the Antibacterial Effect Using the Well-Established Methods.

of the inhibition zone was seen on the A. baumannii ATCC sample. The diameter of the inhibition zone for the nettle extract, shallot extract and the silver nanoparticles was 16,26 and $15 \mathrm{~mm}$, respectively. The minimum size of the inhibition zone was seen on the A6 sample. The diameter of the inhibition zone for the nettle extract, shallot extract and silver nanoparticles plates was 9,20 and $11 \mathrm{~mm}$ respectively.

\section{MIC and MBC Results}

The minimum inhibitory concentration (MIC) and the minimum bactericidal concentration $(\mathrm{MBC})$ results of the nettle alcoholic extract, the shallot alcoholic extract and the silver nanoparticles have been shown in Table 2.

\section{Checkerboard Test}

The FIC index was calculated using formula 1 to determine the kind of interaction. In this study, the amounts of differential inhibitory concentration were determined through the modified dilution checkerboard method. The resulted FIC values for the nettle and the shallot alcoholic extracts have been presented in Tables 3 and 4. The interaction of nettle extract and silver nanoparticles had a synergistic effect and the interaction of shallot extract and silver nanoparticles had additive effects.

\section{Discussion}

The spread of the multi-drug resistant pathogens is a great threat in the therapeutic system all over the world. The extensive consumption and inappropriate prescription of antibiotics leads to bacterial resistance. Today, the spread of multi-drugs resistant bacteria in the ICU is increasing significantly. Among these multi-drug resistant bacteria, A. baumannii is one of the most important factors for creating hospital infections, especially in the ICU. ${ }^{5}$

Silver nanoparticles as well as different combinations with the base of silver show extensive antibacterial effects against pathogens. ${ }^{30}$ These substances prevent the colonization of bacteria on prosthetics, catheters, etc. ${ }^{21}$ Silver nanoparticles make changes in morphology and permeability in the bacterial membrane by attaching to the proteins of the 
Table 2. The Results of the MBC and the MIC of the Nettle Alcoholic Extract and the Silver Nanoparticles and the Shallot Alcoholic Extract

\begin{tabular}{|c|c|c|c|c|c|c|}
\hline Sample & Nettle MIC (mg/mL) & Nettle MBC $(\mathrm{mg} / \mathrm{mL})$ & $\begin{array}{l}\text { Silver Nanoparticles MIC } \\
(\mathrm{mg} / \mathrm{mL})\end{array}$ & $\begin{array}{l}\text { Silver Nanoparticles } \\
\text { MBC }(\mathrm{mg} / \mathrm{mL})\end{array}$ & $\begin{array}{l}\text { Shallot MIC (mg/ } \\
\mathrm{mL})\end{array}$ & $\begin{array}{c}\text { Shallot MBC } \\
(\mathrm{mg} / \mathrm{mL})\end{array}$ \\
\hline ATCC & 1.81 & 3.62 & 0.65 & 1.3 & 1.4 & 2.81 \\
\hline A6 & 3.62 & 3.62 & 0.65 & 1.3 & 2.81 & 2.81 \\
\hline A81 & 3.62 & 7.25 & 0.65 & 1.3 & 2.81 & 2.81 \\
\hline A223 & 3.62 & 3.62 & 0.65 & 1.3 & 2.81 & 2.81 \\
\hline A194 & 3.62 & 3.62 & 0.65 & 1.3 & 2.81 & 2.81 \\
\hline
\end{tabular}

Table 3. The Interaction of the Nettle Alcoholic Extract With the Silver Nanoparticles

\begin{tabular}{lcccc}
\hline Isolates & FIC of the Nettle Extract & FIC of the Silver Nanoparticles & FIC $_{\text {indexA }}$ & The Kind of Interaction \\
\hline ATCC & 0.5 & 0.0625 & 0.5 & Synergism \\
A6 & 0.25 & 0.25 & 0.5 & Synergism \\
\hline
\end{tabular}

Note: The $\mathrm{FIC}_{\text {indexA }}$ represents the total differential inhibitory concentration of the nettle extract and the silver nanoparticles.

Table 4. The Interaction of the Shallot Alcoholic Extract With the Silver Nanoparticles

\begin{tabular}{lcccc}
\hline Isolates & FIC of the Nettle Extract & FIC of the Silver Nanoparticles & FIC $_{\text {indexB }}$ & 1 \\
\hline ATCC & 0.5 & 0.5 & The Kind of Interaction & 1 \\
A6 & 0.5 & 0.5 & Additive \\
\hline
\end{tabular}

Note: The $\mathrm{FIC}_{\text {index }}$ represents the total differential inhibitory concentration of the shallot extract and the silver nanoparticles.

surface of the bacterial membrane. They also inhibit the DNA synthesis that lead to the cellular death. ${ }^{31,32}$ KarimiPoor et al showed that silver nanoparticles have antibacterial effect against $A$. baumannii and it can prevent the growth of this bacterium. ${ }^{33}$ Behdad et al demonstrated that the silver nanoparticles have an effect on the efflux pumps of $A$. baumannii and through this process it can destroy the cell membrane of A. baumannii. ${ }^{34}$ The results of this study were in consistency with the above mentioned studies. Actually, the synthesized silver nanoparticles can inhibit the growth of $A$. baumannii isolates and lead to the bacterial death. The effect of silver nanoparticles on A. baumannii isolates showed that the maximum diameter of growth inhibition zones in ATCC isolate was $15 \mathrm{~mm}$ and the minimum diameter of growth inhibition zones in A194 isolate was $12 \mathrm{~mm}$. The minimum inhibitory concentration was $0.65 \mathrm{mg} / \mathrm{mL}$ in all isolates, and the minimum bactericidal concentration was $1.3 \mathrm{mg} / \mathrm{mL}$ in all isolates.

One medicinal plant which is used in traditional medicine is the Iranian shallot with the scientific name of Allium hirtifolium Boiss and has different properties including antibacterial property. ${ }^{14} \mathrm{~A}$ research conducted by Hasani et al showed that the shallot essence has a high potential to destroy Listeria monocytogenes. ${ }^{32}$ Aleebrahim-Dehkordy et al demonstrated that the shallot extract had an effective antibacterial property against Enterococcus faecalis which was resistant to penicillin. In this study, the shallot extract had an effective antibacterial property against both standard and resistant isolates..$^{35}$ The maximum size of growth inhibition zones in the ATCC isolate was $26 \mathrm{~mm}$ and the minimum size of growth inhibition zones in the A6 isolate was $20 \mathrm{~mm}$. The minimum inhibitory concentration of shallot extraction on ATCC isolate was $1.4 \mathrm{mg} / \mathrm{mL}$, and was $2.81 \mathrm{mg} / \mathrm{mL}$ in the other resistant isolates. The minimum bactericidal concentration was $2.81 \mathrm{mg} / \mathrm{mL}$ in all isolates. The results indicated that the shallot extract had an antibacterial effect against both standard and resistant $A$. baumannii although it had a better effect on standard isolate.

A research conducted by Modaressi et al showed that the nettle alcoholic extract has an inhibitory effect on the bacterial growth of Vibrio parahaemolyticus and Bacillus cereus. ${ }^{36}$ In another study, the antibacterial effect of this extract was seen on clinical resistant gram-positive and gram-negative bacteria such as Staphylococcus epidermidis and Escherichia coli. The alcoholic extract of nettle destroys the integrity of the cell wall of bacteria and finally leads to the bacterial death. ${ }^{15}$ This study also showed that the alcoholic extract of the nettle has antibacterial property on standard and resistant A. baumannii isolates. The best effect was seen on ATCC isolate and the least effect was seen on resistant A6 isolate. The diameter of growth inhibition zones was $16 \mathrm{~mm}$ and 9 $\mathrm{mm}$ respectively. Nettle extract inhibits the growth of all $A$. baumannii isolates. It can inhibit the growth of ATCC isolate in the concentration of $1.81 \mathrm{mg} / \mathrm{mL}$ and the other resistant isolates in the concentration of $3.62 \mathrm{mg} / \mathrm{mL}$. The $\mathrm{MBC}$ of nettle extract against ATCC, A6, A223, and A194 isolates was $3.62 \mathrm{mg} / \mathrm{mL}$ and was $7.25 \mathrm{mg} / \mathrm{mL}$ for the AR and A81 isolates. In general, the extract of shallot against $A$. baumannii isolates was more effective than the extract of nettle.

Recently, the combination of different drugs has been used for the treatment of many infectious diseases to reduce toxicity and increase medicinal effect against resistant bacteria. ${ }^{37}$ A study which has been conducted in 2014 showed that the combination of Drosera binate extract with the silver nanoparticles was more effective compared to singularly using the silver nanoparticles or Drosera binate 
extract against resistant Staphylococcus aureus isolates. ${ }^{22}$ In another research, the antimicrobial property of the oil essence of Mentha piperita with the silver ions against S. aureus, E. coli, and Candida albicans was investigated. The antibacterial synergism activity was found between the metal ions which has hydrophobic property, and oil essence which had hydrophobic activity. ${ }^{38}$ Smekavola et al investigated the antibacterial property of the combination of some antibiotics with the silver nanoparticles. Their results showed that some bacteria which were intrinsically resistant to specific antibiotics could become susceptible to them through the use of the combination of these antibiotics with silver nanoparticles. ${ }^{36}$ The results of these studies were in consistency with the results of the present study. In this study, the checkerboard method was used to measure the synergism effect of these two compounds and it was determined that the combination of silver nanoparticles with the nettle alcoholic extract against ATCC and resistant A. baumannii isolates had a synergistic effect. The combination of silver nanoparticles with the shallot alcoholic extract against ATCC and resistant A. baumannii isolates had the additive effect. It seems that the extracts of nettle or shallot can make changes on the bacterial cell wall. Then the permeability of the cell wall increases and the silver nanoparticles can enter through it. Finally, the silver nanoparticles inhibit the cell division cycle by inhibiting the DNA synthesis.

\section{Conclusions}

It seems that the rise of multidrug-resistant bacteria has led to an increase in the mortality of patients, hospitalization time and expenses. Due to the rise of antibiotics resistance, it is necessary to find some accessible and affordable substances with minimum side effects. The medicinal plants which have different properties have attracted the attention of scientists from long time ago. Using these natural resources in combination with nanobiotechnology products can provide more effective drugs against multidrug resistant bacteria.

\section{Authors' Contributions}

SM and ASTB designed and supervised the research, SZA and MAK performed the experiment and wrote the manuscript. SM and ASTB made the final revising of the manuscript. All the authors approved the final revision of the manuscript.

\section{Conflict of Interest Disclosures}

The authors declare they have no conflicts of interest.

\section{Acknowledgments}

This study was supported by Iran University of Medical Sciences, Tehran, Iran. The authors would like to express their special appreciation to Somayeh Samimi from the Ebnemasouyeh Pharmaceutical Company for all her help throughout this research.

\section{References}

1. Magiorakos AP, Srinivasan A, Carey RB, et al. Multidrug-resistant, extensively drug-resistant and pandrug-resistant bacteria: an international expert proposal for interim standard definitions for acquired resistance. Clin Microbiol Infect. 2012;18(3):268-281. doi:10.1111/j.1469-0691.2011.03570.x.

2. Li B, Webster TJ. Bacteria antibiotic resistance: new challenges and opportunities for implant-associated orthopedic infections. J Orthop Res. 2018;36(1):22-32. doi:10.1002/jor.23656.
3. Luyt C-E, Bréchot N, Trouillet JL, Chastre J. Antibiotic stewardship in the intensive care unit. Crit Care. 2014;18(5):480. doi:10.1186/ s13054-014-0480-6.

4. Mohajeri P, Farahani A, Feizabadi MM, Ketabi H, Abiri R, Najafi F. Antimicrobial susceptibility profiling and genomic diversity of Acinetobacter baumannii isolates: a study in western Iran. Iran J Microbiol. 2013;5(3):195-202.

5. Maraki S, Mantadakis E, Mavromanolaki VE, Kofteridis DP, Samonis G. A 5-year surveillance study on antimicrobial resistance of Acinetobacter baumannii clinical isolates from a tertiary Greek hospital. Infect Chemother. 2016;48(3):190-198. doi:10.3947/ ic. 2016.48.3.190.

6. Brunner LS. Brunner \& Suddarth's textbook of medical-surgical nursing. Lippincott Williams \& Wilkins; 2010.

7. Almaghrabi MK, Joseph MRP, Assiry MM, Hamid ME. Multidrugresistant Acinetobacter baumannii: an emerging health threat in Aseer Region, Kingdom of Saudi Arabia. Can J Infect Dis Med Microbiol. 2018;2018:9182747. doi:10.1155/2018/9182747.

8. Bakal SN, Bereswill S, Heimesaat MM. Finding novel antibiotic substances from medicinal plants--antimicrobial properties of Nigella sativa directed against multidrug resistant bacteria. Eur J Microbiol Immunol (Bp). 2017;7(1):92-98. doi:10.1556/1886.2017.00001.

9. Singh G, Maurya S, de Lampasona MP, Catalan CAN. Studies on essential oils, Part 41. Chemical composition, antifungal, antioxidant and sprout suppressant activities of coriander (Coriandrum sativum) essential oil and its oleoresin. Flavour Fragr J. 2006;21(3):472-479. doi:10.1002/ffj.1608.

10. Ghasemi Pirbalouti A, Setayesh M, Siahpoosh A, Mashayekhi H. Antioxidant activity, total phenolic and flavonoids contents of three herbs used as condiments and additives in pickles products. Herba Pol. 2013;59(3):51-62. doi:10.2478/hepo-2013-0016.

11. Taran $M$, Rezaeian $M$, Izaddoost $M$. In vitro antitrichomonas activity of Allium hirtifloium (Persian Shallot) in comparison with metronidazole. Iran J Public Health. 2006;35(1):92-94.

12. Benkeblia N. Antimicrobial activity of essential oil extracts of various onions (Allium cepa) and garlic (Allium sativum). LWT - Food Sci Technol. 2004;37(2):263-268. doi:10.1016/j. Iwt.2003.09.001.

13. Jafarian A, Ghannadi A, Elyasi A. The effects of Allium hirtifolium Boiss. on cell-mediated immune response in mice. Iran J Pharm Res. 2010;2(1):51-55. doi:10.22037/ijpr.2010.36.

14. Ismail $\mathrm{S}$, Jalilian FA, Talebpour AH, et al. Chemical composition and antibacterial and cytotoxic activities of Allium hirtifolium Boiss. Biomed Res Int. 2013;2013:696835. doi:10.1155/2013/696835.

15. Motamedi H, Seyyednejad SM, Bakhtiari A, Vafaei M. Introducing Urtica dioica, a native plant of khuzestan, as an antibacterial medicinal plant. Jundishapur J Nat Pharm Prod. 2014;9(4):e15904. doi:10.17795/jjnpp-15904.

16. Habibi Lahigi S, Amini K, Moradi P, Asaadi K. Investigating the chemical composition of different parts extracts of bipod nettle Urtica dioica L. in Tonekabon region. Iranian Journal of Plant Physiology. 2011;2(1):339-342. doi:10.22034/ijpp.2011.540721.

17. Ramtin M, Massiha A, Khoshkholgh-Pahlaviani MRM, Issazadeh K, Assmar M, Zarrabi S. In vitro antimicrobial activity of Iris pseudacorus and Urtica dioica. Zahedan Journal of Research in Medical Sciences. 2014;16(3):35-39.

18. Majd A, Mehrabian S, Jafari Z. The study of antimicrobial effects of Urtica dioicas extract. Iranian Journal of Medicinal and Aromatic Plants. 2003;19(3):287-312.

19. Lara HH, Ayala-Núñez NV, Turrent LdCl, Rodríguez-Padilla C. Bactericidal effect of silver nanoparticles against multidrugresistant bacteria. World J Microbiol Biotechnol. 2010;26(4):615621. doi:10.1007/s11274-009-0211-3.

20. Theivasanthi T, Alagar M. Anti-bacterial studies of silver nanoparticles. https://arxiv.org/abs/1101.0348. Published January 1, 2011.

21. Panáček A, Kvítek L, Prucek R, et al. Silver colloid nanoparticles: 
synthesis, characterization, and their antibacterial activity. J Phys Chem B. 2006;110(33):16248-16253. doi:10.1021/jp063826h.

22. Krychowiak M, Grinholc M, Banasiuk R, et al. Combination of silver nanoparticles and Drosera binata extract as a possible alternative for antibiotic treatment of burn wound infections caused by resistant Staphylococcus aureus. PLoS One. 2014;9(12):e115727. doi:10.1371/journal.pone.0115727.

23. Patel JB. Performance standards for antimicrobial susceptibility testing. Clinical and Laboratory Standards Institute; 2017.

24. Rashid MU, Bhuiyan MKH, Quayum ME. Synthesis of silver nano particles (Ag-NPs) and their uses for quantitative analysis of vitamin C tablets. Dhaka Univ J Pharm Sci. 2013;12(1):29-33. doi:10.3329/dujps.v12i1.16297.

25. Zakerin A, Ahmadi E, Fasihi-Ramandi M, et al. The Effects of Ecologic Condition on Antimicrobial Activity of Endemic Herbal Extracts in Fars Province. Journal of Fasa University of Medical Sciences. 2015;5(1):111-119. [Persian].

26. Clinical and Laboratory Standards Institute (CLSI). Performance standards for antimicrobial susceptibility testing; Twenty-first Informational Supplement. CLSI Document M100-S21. Wayne, PA: CLSI; 2011.

27. Clinical and Laboratory Standards Institute (CLSI). Methods for Determining Bactericidal Activity of Antimicrobial Agents. CLSI Document M26-A. Wayne, PA: CLSI; 1999.

28. Romano CS, Abadi K, Repetto V, Vojnov AA, Moreno S. Synergistic antioxidant and antibacterial activity of rosemary plus butylated derivatives. Food Chem. 2009;115(2):456-461. doi:10.1016/j. foodchem.2008.12.029.

29. Kaduková J, Velgosová O, Mražíková A, Marcinčáková R. The effect of culture age and initial silver concentration on biosynthesis of Ag nanoparticles. Nova Biotechnol Chim. 2014;13(1):28-37. doi:10.2478/nbec-2014-0004.

30. Kohsari I, Mohammad-Zadeh M, Minaeian S, et al. In vitro antibacterial property assessment of silver nanoparticles synthesized by Falcaria vulgaris aqueous extract against MDR bacteria. J Solgel Sci Technol. 2019;90(2):380-389. doi:10.1007/ s10971-019-04961-0.

31. Stone V, Donaldson K. Nanotoxicology: signs of stress. Nat Nanotechnol. 2006;1(1):23-24. doi:10.1038/nnano.2006.69.

32. Huang L, Dai T, Xuan Y, Tegos GP, Hamblin MR. Synergistic combination of chitosan acetate with nanoparticle silver as a topical antimicrobial: efficacy against bacterial burn infections. Antimicrob Agents Chemother. 2011;55(7):3432-3438. doi:10.1128/aac.01803-10.

33. Karimipour SN, Tanomand A, Rostamnia S. The Antibacterial Activity Evaluation of the Nanoparticles of Silver on Acinetobacter Baumannii. Journal of Fasa University of Medical Sciences. 2016;6(2):264-270. [Persian].

34. Behdad R, Mirzaie A, Zare Karizi S. Green synthesis of silver nanoparticle using Acroptilon repens extract and evaluation of its anti-efflux activity against Acinetobacter bumanni clinical isolates. Journal of Microbial World. 2017;10(3):210-221. [Persian].

35. Aleebrahim-Dehkordy E, Rafieian-Kopaei M, Ghasemi-Pirbalouti A, Bahmani M. The antibacterial effects of wild and cultivated Allium hirtifolium Boiss on Pseudomonas aeruginosa and Enterococcus faecalis and antibiotic resistance patterns of the strains using disk diffusion. J Chem Pharm Sci. 2016;9(4):34093413.

36. Smekalova M, Aragon V, Panacek A, Prucek R, Zboril R, Kvitek L. Enhanced antibacterial effect of antibiotics in combination with silver nanoparticles against animal pathogens. Vet J. 2016;209:174179. doi:10.1016/j.tvjl.2015.10.032.

37. Chou TC. Theoretical basis, experimental design, and computerized simulation of synergism and antagonism in drug combination studies. Pharmacol Rev. 2006;58(3):621-681. doi:10.1124/pr.58.3.10.

38. Ahmad A, Khan A, Samber N, Manzoor N. Antimicrobial activity of Mentha piperita essential oil in combination with silver ions. Synergy. 2014;1(2):92-98. doi:10.1016/j.synres.2014.11.001. 